\title{
Voltage Control for Enhanced Power Electronic Efficiency in Series Hybrid Electric Vehicles
}

\author{
Mark Roche, Wassif Shabbir, and Simos A. Evangelou
}

\begin{abstract}
The paper presents a DC-link voltage control scheme by which the power losses associated with the power electronic converters of a series Hybrid Electric Vehicle (HEV) powertrain are reduced substantially. A DC-link commonly connects the three powertrain branches associated with series HEVs, presently interfaced by a three-phase rectifier, a threephase inverter and a Dual Active Bridge (DAB) DC/DC converter. Dynamic efficiency models of the converters are developed and a methodology is proposed by which the DC-link voltage is varied with respect to its default value, based on the ratio between the battery and DC-link voltages. The voltage control scheme introduced varies the phase shift between the gating signals of the two DAB converter bridges, proportionally to the ratio of converter input voltage to output voltage referred to the transformer primary. This level of instantaneous control forces the converter to operate in boost mode when the battery charges and buck mode when the battery discharges, allowing the converter to persistently avoid Hard Switching (HS) losses over its entire operating range. The control scheme is tested in simulations with a full HEV model by comparing its performance with constant voltage and unity voltage conversion ratio PI control schemes. The scheme proves most effective for vehicles with high hybridization factor, driving in an urban environment.
\end{abstract}

\section{INTRODUCTION}

$\mathbf{S}$ INCE 1970, the global Greenhouse Gas (GHG) emissions from transportation have increased by more than a factor of two. The contribution from road vehicles towards transportation emissions has increased over this period from $59.85 \%$ to $72.06 \%$ [1]. The HEV represents a step towards sustainable transportation, by reducing fossil fuel consumption [2]. By minimizing power loss within the HEV powertrain, power demand is reduced for a given road load, and hence the sustainable impact of this technology is enhanced. As mentioned in [3], efficiency is one of the key drivers behind the next generation of vehicles, and significant progress has been made through intelligent supervisory controllers over the past decade [4]. This paper proposes a DC-link voltage control scheme which enhances the combined efficiency of the three power electronic converters of a series HEV powertrain, in a further step towards achieving this goal.

Copyright (c) 2015 IEEE. Personal use of this material is permitted. However, permission to use this material for any other purposes must be obtained from the IEEE by sending a request to pubs-permissions@ieee.org.

M. Roche is with Jaguar Land Rover and was previously with the Department of Electrical and Electronic Engineering, Imperial College London, London SW7 2AZ, UK (e-mail: mark.roche13@alumni.imperial.ac.uk).

W. Shabbir and S. A. Evangelou are with the Department of Electrical and Electronic Engineering, Imperial College London, London SW7 2AZ, UK (e-mail: wassif.shabbir07@imperial.ac.uk, s.evangelou@imperial.ac.uk).

Supporting data available on request from cap-publications@imperial.ac.uk
A wide range of research exists on HEVs for various architectures [5]. For topologies in which the voltage of the battery and DC-link are not equal, the inclusion of a DC/DC converter is necessary. The literature reviewed included standard boost converters [6], [7], three-level converters [8], and dual bridge isolated converters [9]-[16]. Transformer isolation provides advantages in terms of personnel safety and noise reduction [17]. Less common arrangements analyzed include the combined SEPIC and Luo converters detailed in [18]. The inclusion of a DC/DC converter enables control the DC-link voltage via the gating signals of the integral power electronic switches. Despite this, lack of physical space in the vehicle sometimes results in exclusion of the DC/DC converter in the $\mathrm{HEV}$ design [6]. An understanding of optimal voltage control methods lends itself to enhancing overall HEV efficiency, as the DC-link voltage influences the performance of all power electronic converters within a series powertrain.

Several approaches have been proposed for variable DClink voltage and DC/DC converter control. A polynomial DC/DC converter control scheme is detailed in [19], which emphasizes the improvement of operation robustness as compared to PI control, rather than improving energy efficiency. Similarly, [20] also aims to improve operation reliability by implementing a constant modulation index control for the DC-link voltage. The work presented in [6] compares the performance of two electric drive systems. The first comprises of a battery-powered inverter, while the second incorporates a bidirectional boost converter between the battery and inverter, which facilitates DC-link voltage control. Both systems supply a Permanent Magnet Synchronous Motor (PMSM). A scheme is developed which varies the DC-link voltage proportionally with PMSM speed. The performance of the first topology is compared with that of the variable voltage bidirectional scheme, and the latter is shown to achieve improvements in terms of global drive, inverter and PMSM efficiencies. Although these single source models are less complex than the dual source model presented in this paper, the achievements of [6] have acted as inspiration for the work herein.

The main contribution of this paper is a proportional control law for the phase shift between the switching waveforms of the bridges of a DAB DC/DC converter which interfaces with the DC-link and battery of a series HEV powertrain, to control the dynamic DC-link voltage. The controller achieves a reduction of both DC/DC converter and total powertrain power electronic losses for an urban drivecycle, while achieving approximately the same level of total powertrain power electronic losses as the most efficient PI control scheme tested, for a highway drive cycle. A further contribution is the development of the 


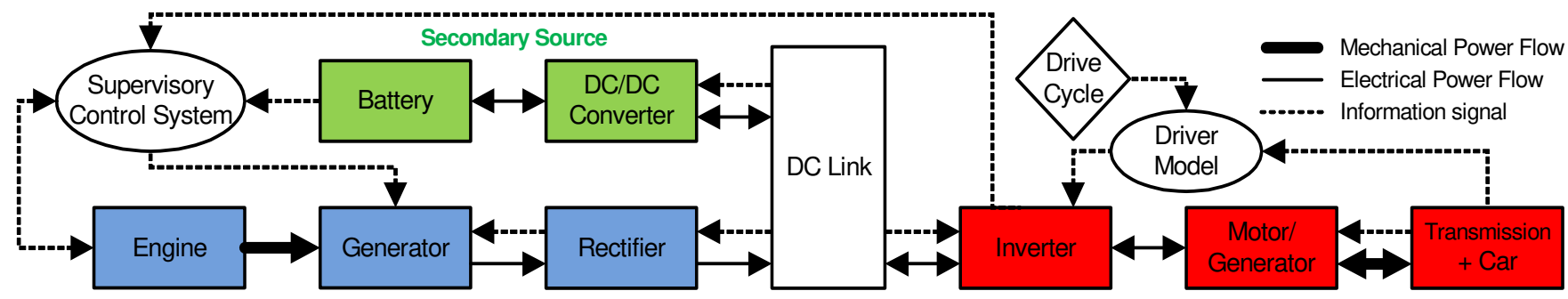

Primary Source

Propulsion Load

Fig. 1. Block diagram of the series HEV powertrain used in this work.

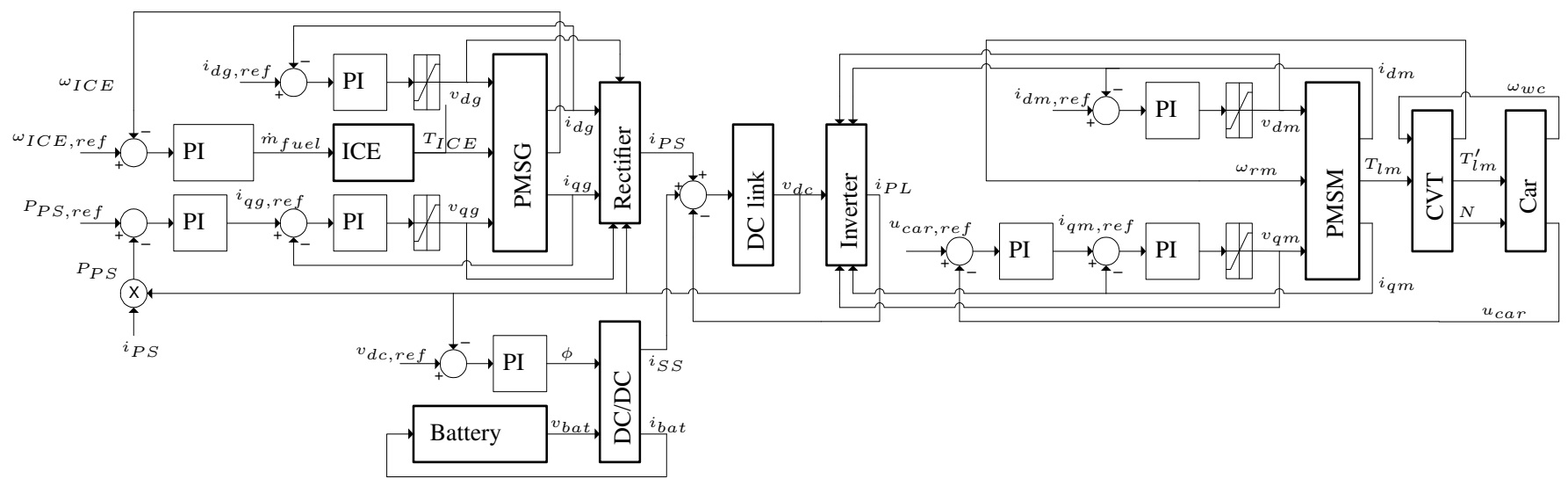

Fig. 2. Control schematic showing the interconnection of the internal combustion engine (ICE), PMSG, rectifier, battery, DC/DC converter, inverter, PMSM, continuously variable transmission (CVT) and car, and the related control loops.

methodology to select the best nominal DC-link voltage to maximize the efficiency of the inverter and rectifier.

The paper is structured as follows. Section II details: (a) the base HEV model that is used to conduct the study, (b) respectively the modeling of the power loss and analysis of performance of the inverter and rectifier for varying motor and generator operating conditions, and (c) operating mode dependent switching and conduction loss models for the DAB converter. Section III describes the Constant Voltage PI (CVPI), Unity Ratio PI (URPI) and the proportional DC-link control schemes developed and tested in the paper. Simulation results are presented in Section IV, comparing the performance of the proposed control schemes and showing the energy savings achieved by the best scheme. Final conclusions drawn are presented in Section V.

\section{Modeling}

The HEV model used in this paper is a modified version of that presented in [21] and [22]. Changes are made to this model in relation to the inverter and rectifier modulation strategy, and the DC/DC converter model. Furthermore, dynamic efficiency modeling is also introduced for all the converters. Conduction and switching losses of the inverter and rectifier are dependent on converter modulation indices, which also represent boundaries in relation to feasible motor and generator operating regions. The switching loss of these converters is proportional to the switching frequency, and current through and voltage over the switched elements. Conduction loss of the DC/DC converter is dictated by RMS and average currents. Switching varies between high loss and lossless depending on the operating variables. The HEV model and inverter, rectifier and DC/DC converter loss models are detailed in this section.

\section{A. Vehicle Model}

The block diagram of the HEV powertrain is given in Fig. 1 and the control schematic is shown in Fig. 2. A diesel engine and DC battery respectively act as the primary and secondary HEV energy sources. The relative proportion of power supplied by the two sources is decided by a Supervisory Control System (SCS), based on the motor load and the battery State of Charge (SOC). The Thermostat SCS is given in [23] and [24], and works as follows. The engine will either be operating at its optimal point $(25 \mathrm{~kW}, 1600 \mathrm{rpm})$ or producing zero power. When inverter demand exceeds $25 \mathrm{~kW}$, both sources supply power together in hybrid mode. Engine only supply occurs when the battery SOC is at or below $50 \%$, and will continue to supply until the SOC reaches $80 \%$. At this stage, the battery discharges, in battery-only operation, until its SOC reaches $50 \%$ [25].

The PMSG supplies power to the rectifier and the PMSM accepts power from the inverter. PMSM torque is relayed to the wheels through a continuously variable transmission. As detailed in [21], for both the PMSG and PMSM, the direct current is controlled to $0 \mathrm{~A}$. To achieve this, the reference currents $i_{d m, r e f}$ and $i_{d g, r e f}$ given in the powertrain control diagram (Fig. 2) are set to $0 \mathrm{~A}$. The respective quadrature 

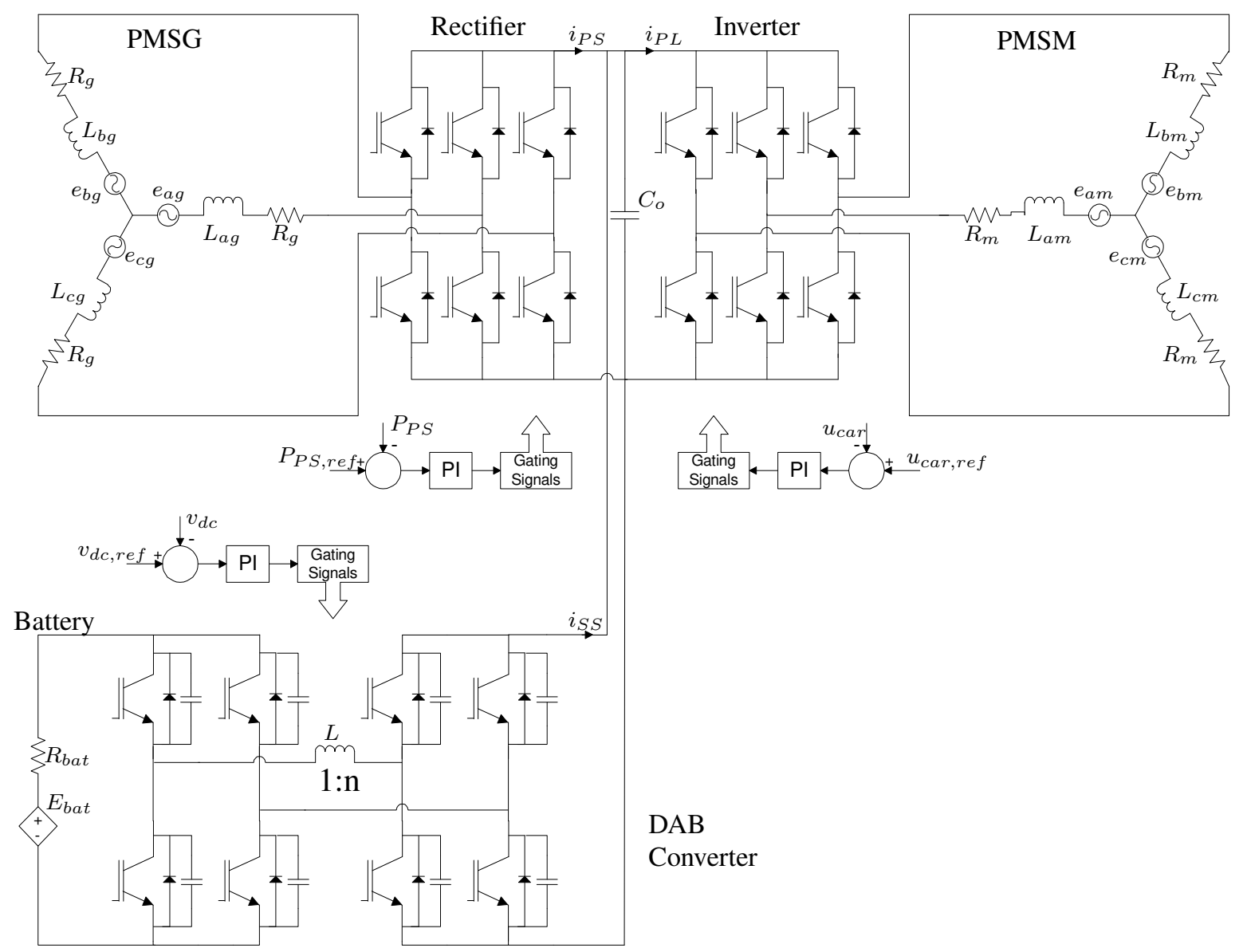

Fig. 3. The series HEV powertrain includes the PMSG, rectifier, battery, DAB converter, inverter and PMSM, as illustrated by the circuit diagram. Symbols $R, L$ and $e$ represent phase resistances, inductances and induced emfs respectively. Subscripts $a, b$ and $c$ correspond to the individual phases, and subscripts $g, m$ and ref correspond to 'generator', 'motor' and 'reference'. $E_{b a t}$ and $R_{b a t}$ correspond to the battery emf and internal resistance, while $L$ is the inductance associated with the DC/DC converter and $C_{0}$ is the DC-link capacitance. $i_{P S}, i_{S S}$ and $i_{P L}$ are the primary source (PMSG-branch), secondary source (battery-branch) and propulsion load (PMSM-branch) DC currents. The control signals are $v_{d c}$ (the DC-link voltage), $P_{P S}$ (the primary source power) and $u_{\text {car }}$ (the forward speed of the car).

currents of the PMSG and PMSM are controlled to manipulate the machine torque to achieve desired PMSG power output and vehicle speed. The base model given in [21] assumes constant efficiencies of $94.61 \%$ for the inverter and rectifier, and $96 \%$ for the DC/DC converter. The work done in this paper, replaces these figures with dynamic efficiency models. Prior to the present work, PI control has been used to maintain a DC-link voltage of $700 \mathrm{~V}$.

\section{B. Inverter and Rectifier}

The inverter and rectifier operate based on a sinusoidal Pulse Width Modulation (PWM) method, as opposed to the Space Vector Modulation (SVM) form of PWM assumed in the base model. As shown in Fig. 3 the rectifier design is the same as that of the inverter, although they generally realize opposite goals. The inverter converts DC to three-phase AC when power is demanded by the motor, only operating conversely during regenerative braking. The rectifier converts three-phase AC to DC. Switching is dictated by three-phase sinusoidal PWM (described in [26] and [27]), which compares three sinusoidal modulating signals (at the desired motor voltage frequency) with a common high-frequency triangular carrier signal. Linear modulation occurs if the amplitude of the modulating signals is below that of the carrier signal. The converter modulation index $(M)$ is the ratio of modulating and carrier signal amplitudes [27]. To avoid overmodulation, the following condition must be obeyed:

$$
0 \leq M \leq 1
$$

For a given DC-link voltage $\left(v_{d c}\right)$, the amplitude of AC phase voltage $\left(v_{p h}\right)$ of the inverter and rectifier is limited by its modulation index [27]:

$$
v_{p h}=\frac{M v_{d c}}{2}
$$

For $M=1$ this equation represents a constraint for the feasible operating region of the PMSM and PMSG, denoting the boundary between linear modulation and overmodulation. This constraint varies for a varying DC-link voltage. The conduction losses of the inverter are approximated by [28], [29]:

$$
P_{\text {cond }}=6\left(i_{p k} v_{f 0}\left(\frac{1}{2 \pi}-\frac{M}{8}\right)+i_{p k}^{2} r_{f}\left(\frac{1}{8}-\frac{M}{3 \pi}\right)\right.
$$




$$
\left.+r_{c e} i_{p k}^{2}\left(\frac{1}{8}+\frac{M}{3 \pi}\right)+v_{c 0} i_{p k}\left(\frac{1}{2 \pi}+\frac{M}{8}\right)\right),
$$

where $i_{p k}$ is the peak $\mathrm{AC}$ current from the inverter, $v_{f 0}$ is the diode forward voltage corresponding to zero current, $r_{f}$ is the diode forward resistance, $r_{c e}$ is the IGBT collector emitter resistance and $v_{c 0}$ is the IGBT forward voltage corresponding to zero collector current. The power factor terms shown in [28] are omitted in Eq. 3. As mentioned previously, PMSM and PMSG direct currents are controlled to $0 \mathrm{~A}$, which yields close to unity power factor for non-salient structures $\left(L_{d}=L_{q}\right)$ except at very high loads [30], [31]. This approximation is sufficiently accurate for this work. The switching losses of the inverter are given by [29]:

$$
P_{s w}=6 \frac{f_{i} v_{d c} i_{p k}}{v_{r e f} i_{r e f} \pi}\left(E_{o n, r e f}+E_{o f f, r e f}+E_{r r, r e f}\right)
$$

where $f_{i}$ is the switching frequency (carrier signal frequency) of the inverter, $E_{\text {on, ref }}$ is the reference IGBT turn on energy loss, $v_{\text {ref }}$ is the voltage at which reference energy loss is measured, $i_{\text {ref }}$ is the current at which reference energy loss is measured, $E_{\text {off,ref }}$ is the reference IGBT turn off energy loss and $E_{r r, r e f}$ is the reference diode reverse recovery energy loss. Reference values are obtained from the corresponding device datasheet. Summing the conduction and switching losses to acquire the total power loss $P_{\text {loss }}^{i n v}$, the dynamic efficiency expression of the inverter is found. The expression differs based on the direction of power flow:

$$
\begin{aligned}
\eta_{i n v}^{d c-a c} & =\frac{T_{e m} \omega_{r m}+\frac{3}{2} R_{m} i_{q m}^{2}}{T_{e m} \omega_{r m}+\frac{3}{2} R_{m} i_{q m}^{2}+P_{l o s s}^{i n v}}, \\
\eta_{i n v}^{a c-d c} & =\frac{T_{e m} \omega_{r m}+\frac{3}{2} R_{m} i_{q m}^{2}+P_{l o s s}^{i n v}}{T_{e m} \omega_{r m}+\frac{3}{2} R_{m} i_{q m}^{2}}
\end{aligned}
$$

where $T_{e m}, \omega_{r m}, i_{q m}$ and $R_{m}$ are the electromagnetic torque, mechanical speed, quadrature current and stator resistance of the PMSM. The term proportional to the square of quadrature current is equal to the PMSM stator resistive power loss as per, while the numerator of Eq. 5 corresponds to the total power into the PMSM out of the inverter. Conduction, switching and total rectifier losses are calculated using the same expressions as for the inverter, but using rectifier variables. However, as PMSG power flow is unidirectional, there is a single expression for rectifier efficiency, in which $P_{\text {loss }}^{r e c}$ refers to the sum of rectifier conduction and switching loss:

$$
\eta_{r e c}=\frac{T_{e g} \omega_{r g}-\frac{3}{2} R_{g} i_{q g}^{2}-P_{l o s s}^{r e c}}{T_{e g} \omega_{r g}-\frac{3}{2} R_{g} i_{q g}^{2}},
$$

where $T_{e g}$ (positive for power generation), $\omega_{r g}, i_{q g}$ and $R_{g}$ are the electromagnetic torque, mechanical speed, quadrature current and stator resistance of the PMSG. Similarly to the PMSM equations, the term proportional to the square of quadrature current is equal to the PMSG stator resistive power loss, while the numerator of Eq. 7 is the total power out of the PMSG into the rectifier.

Inverter and rectifier performances are mapped for a number of design DC-link voltages. Both converter switching frequencies are $20 \mathrm{kHz}$. IGBT modules for these converters are selected for each design from the range offered by
TABLE I

IGBT MOdUle SELECTION FOR RECTIFIER, INVERTER AND DAB CONVERTER

\begin{tabular}{|c|c|c|}
\hline IGBT Module & $v_{d c}^{\max }$ & Converter \\
\hline FF300R07ME4_B11 & $650 \mathrm{~V}$ & Inverter \\
\hline FS300R12KE4 & $1200 \mathrm{~V}$ & Inverter \\
\hline FS150R07PE4 & $650 \mathrm{~V}$ & Rectifier \\
\hline FS150R12KT4_B11 & $1200 \mathrm{~V}$ & Rectifier \\
\hline FF100R12RT4 & $1200 \mathrm{~V}$ & DAB \\
\hline FF300R07ME4_B11 & $650 \mathrm{~V}$ & DAB \\
\hline
\end{tabular}

Infineon, by considering the voltage switched, and the RMS and peak current through each switch. Worst case RMS and peak currents are calculated based on maximum torque and speed of the PMSM and PMSG. Based on this means of switch selection, the rectifier and inverter IGBT modules used for different DC-link voltage designs are listed in Table I. Parameters were extracted from the corresponding datasheets for efficiency calculations. The efficiency of the inverter is plotted for varying PMSM load torque and mechanical speed. Maximum load torque and mechanical speed are $400 \mathrm{Nm}$ and $5000 \mathrm{rpm}$ [32]. These represent operating constraints.

Efficiency maximization is only considered for forward driving neglecting regeneration. Therefore, optimization region boundaries are present at $0 \mathrm{Nm}$ and $0 \mathrm{rpm}$. The final operating constraint is that corresponding to the boundary of linear modulation. Design DC-link voltages were tested in $100 \mathrm{~V}$ intervals between $400 \mathrm{~V}$ and $1200 \mathrm{~V}$ inclusive, however 400 $\mathrm{V}$ results in overmodulation of the inverter for the drive cycles considered in Section IV. Results are given for $700 \mathrm{~V}$ and $500 \mathrm{~V}$ in Figs. 4 and 5 respectively. The lower the DC-link voltage, the smaller is the feasible operating region of the PMSM, but the higher is the low speed efficiency. The same

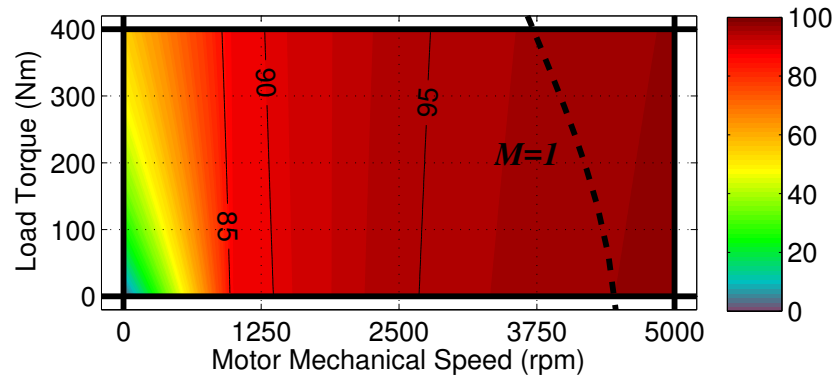

Fig. 4. Efficiency Map of Inverter $\left(v_{d c}^{r e f}=700 \mathrm{~V}\right)$.

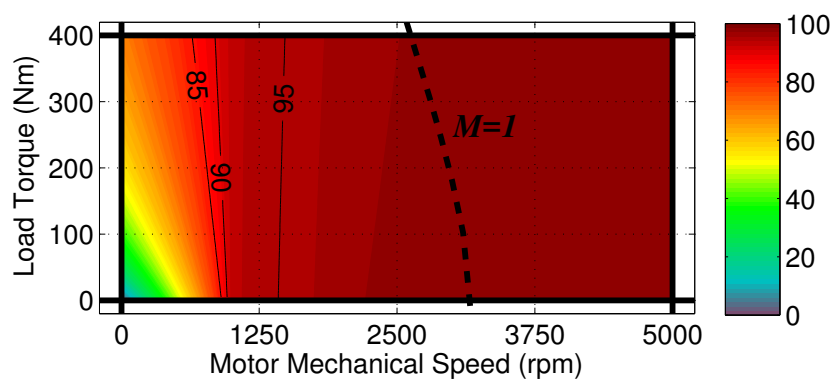

Fig. 5. Efficiency Map of Inverter $\left(v_{d c}^{r e f}=500 \mathrm{~V}\right)$. 


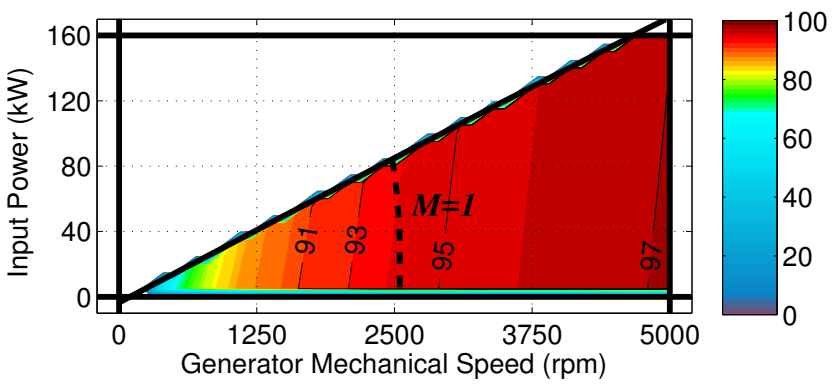

Fig. 6. Efficiency Map of Rectifier $\left(v_{d c}^{r e f}=700 \mathrm{~V}\right)$.

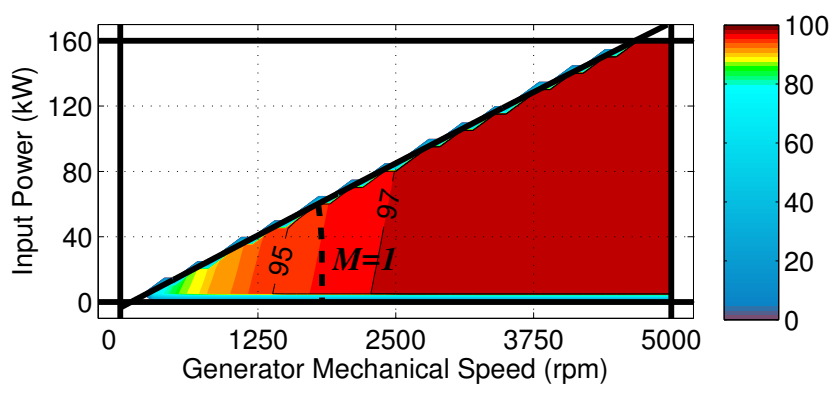

Fig. 7. Efficiency Map of Rectifier $\left(v_{d c}^{r e f}=500 \mathrm{~V}\right)$.

can be said for the rectifier and PMSG, based on Figs. 6 and 7 . The diagonal constraint represents maximum generator torque (340 Nm) [33].

\section{DC/DC Converter}

The DC/DC converter in [21] has been changed from a Dual Half Bridge to a DAB topology as it is more appropriate for the required power range of the battery branch. The DAB converter is composed of two bridges of power electronic switches, connected by an isolation transformer. The primary referred circuit is shown in Fig. 3. An important parameter throughout this paper is the voltage conversion ratio $(d)$. This is the ratio of the primary referred converter output voltage, to the converter input voltage (battery voltage):

$$
d=\frac{v_{o}}{n v_{i}},
$$

where $v_{i}$ is the converter input voltage, $v_{o}$ is the converter output voltage and $n$ is the transformer turns ratio. When $d$ is greater/less than 1, the converter is said to be operating in boost/buck mode [34].

Another important parameter is the phase shift $(\phi)$ between the primary and secondary switch gating signals of the DAB converter, as it determines the direction of power flow. When the phase shift is positive, power flows in the forward direction from the battery to the DC-link, and reverses when phase shift is negative. Average converter power flow is given by the following expression [11], [35]:

$$
P_{\text {avg }}=\frac{v_{i} v_{o} \phi(\pi-\phi)}{2 n \pi^{2} L f},
$$

where $L$ is the primary referred leakage inductance of the intermediate isolation transformer and $f$ is the switching

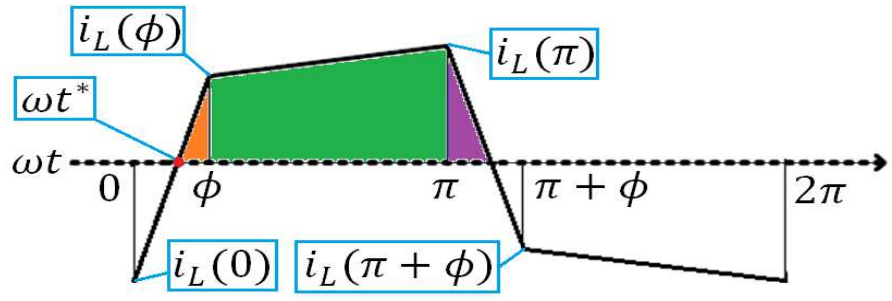

Fig. 8. A cycle of inductor current (forward power, boost mode) of the DAB DC/DC converter [10].

frequency of the DAB converter. As shown in [17], the transformer current is a piece-wise linear sinusoidal approximation based on the changing square wave voltages $v_{p}$ and $v_{s}^{\prime}$. These voltages result from the phase shifted bridge gating signals which have a constant duty cycle of 0.5 . The current and voltage dynamics of the converter throughout a switching cycle is detailed in [36].

For forward power, boost operation, the inductor current is as shown in Fig. 8. The initial inductor zero-crossing of the cycle occurs at $t^{*}$. The inductor current at different stages in the cycle is represented by $i_{L}(0), i_{L}(\phi), i_{L}(\pi)$ and $i_{L}(\pi+\phi)$ and are easily quantified [37]. $t^{*}$ can thus be quantified by acquiring the associated linear relations and calculating the time at which current initially crosses zero in the cycle. For forward power flow:

$$
t^{*}=\frac{\left(v_{i} n+\frac{2}{\pi} v_{o} \phi-v_{o}\right)}{4 f\left(n v_{i}+v_{o}\right)}
$$

The average and RMS current through each of the IGBTs and diodes can be calculated by quantifying the shaded areas in Fig. 8, and using the relationship between operating mode and conduction of components throughout a switching cycle [38]. Average and RMS current expressions equivalent to those given in [10], were found for all combinations of power flow direction and operating mode. A conduction loss model was subsequently created by using these expressions within the basic transformer [14], IGBT and diode [28] conduction loss equations respectively given as follows:

$$
\begin{aligned}
& P_{\text {cond }}^{L}=\left(R_{p}+\frac{R_{s}}{n^{2}}\right) i_{r m s}^{L}{ }^{2} \\
& P_{\text {cond }}^{T}=r_{c e} i_{r m s}^{T}{ }^{2}+v_{c 0} i_{\text {avg }}^{T} \\
& P_{\text {cond }}^{D}=r_{f} i_{r m s}^{D}{ }^{2}+v_{f 0} i_{\text {avg }}^{D}
\end{aligned}
$$

where $i_{r m s}$ and $i_{\text {avg }}$ imply RMS and average current, and the superscripts $L, T$ and $D$ respectively refer to transformer leakage inductance, an active converter IGBT and an active converter diode.

Complete Zero Voltage Switching (CZVS), Incomplete Zero Voltage Switching (IZVS) and Hard Switching (HS) can all occur within the DAB converter. The boundaries between CZVS and IZVS can be derived with help from [38] and are shown on the $d-\phi$ plane in [34]. As stated in [34], at any primary switching instant, the minimum current through the inductance $L$ for which CZVS can occur is given by:

$$
i_{L, \text { min }}^{\text {prim }}=\frac{2 \sqrt{v_{i} v_{o}^{\prime}}}{Z_{r}}, Z_{r}=\sqrt{\frac{L}{C}},
$$


TABLE II

CONDITIONS FOR ZVS (IB=INPUT BRIDGE, OB=OUTPUT BRIDGE)

\begin{tabular}{|c|c|c|c|c|}
\hline Forward & Reverse & $d<1$ & $d>1$ & $d=1$ \\
\hline IB & OB & always & $|\phi| \geq \frac{\pi(d-1)}{2 d}$ & always \\
\hline OB & IB & $|\phi| \geq \frac{\pi(1-d)}{2}$ & always & always \\
\hline
\end{tabular}

where $v_{o}^{\prime}$ is equal to $v_{o}$ referred to the transformer primary and $C$ is the switch snubber capacitance. The minimum current for secondary CZVS is found by dividing by the turns ratio. As shown in [38], CZVS always occurs on one or both of the converter bridges. In the former case, which of the two bridges is capable of losing energy during switching is dependent on the direction of power flow and the mode of operation. In the latter case, the converter is said to be in CZVS mode as both bridges switch in a lossless manner. Whether the bridge will lose energy while switching can be determined by comparing the location of the operating point to the CZVS-IZVS and IZVS-HS boundaries on the $\phi-v_{o}$ or $\phi-d$ plane.

The two IGBTs which switch at lowest current magnitude $\left(i_{L}(\phi)\right.$ and $i_{L}(\pi+\phi)$ in Fig. 8) in the bridge of interest contribute IZVS loss when the inductor current is too low. These switches can be identified using analysis from [38]. By equating the corresponding expression for this current value, to the minimum inductor current of interest (depending on the bridge of interest), linear CZVS-IZVS boundaries can be derived for all four quadrants of the $\phi-v_{o}$ plane.

Similarly, by equating the minimum inductor current of interest to $0 \mathrm{~A}$, linear IZVS-HS boundaries can be derived for all four quadrants of the $\phi-v_{o}$ plane also. The nonlinear expressions for these constraints on the $\phi-d$ plane are given in Table II [34], [38]. Based on the location of the converter operating point on the $\phi-v_{o}$ plane, switching losses are calculated. CZVS is lossless as zero voltage exists over each IGBT at turn-on and turn-off. By analyzing the theoretical waveforms of the voltage over and current through the $\mathrm{DAB}$ IGBTs during turn-on and turn-off, it has been found that approximately zero voltage exists over each IGBT at turnoff in IZVS, though this is not the case for IGBT turn-on. Therefore, IZVS loss at a given switching instant is equal to the sum of IGBT turn-on and snubber capacitance loss. The IGBT turn-on loss [29]:

$$
P_{s w, I G B T}^{I Z V S}=E_{o n, r e f} \frac{i_{L}^{s w} v_{x}}{v_{r e f} i_{r e f}}
$$

and the snubber turn-on loss [12]:

$$
P_{s w, s n u b b e r}^{I Z V S}=C \cdot v_{x}^{2}
$$

are respectively shown for a given current through the leakage inductance $\left(i_{L}^{s w}\right)$, and the voltage over the switched IGBT $\left(v_{x}\right)$ during turn-on of a single IGBT. Snubber capacitance loss is a result of a non-zero voltage over the IGBT snubber capacitance during turn-on.

$v_{x}$ represents the non-zero voltage which is present over the IGBT at the turn-on instant in the case of IZVS. This is $0 \mathrm{~V}$ in the case of CZVS. For HS, $v_{x}$ is equal to the full DC voltage of the converter bridge in question. However for
IZVS, the calculation of $v_{x}$ depends on the quadrant of the $\phi-d$ plane in which the converter is operating. For forward power boost operation, IZVS occurring on the input bridge uses the following calculation of $v_{x}$ :

$$
v_{x}=v_{i}-\frac{\left|i_{L}(0)\right| t_{x}}{2 C}
$$

There are four different calculations of $v_{x}$ - one for each quadrant. $v_{o}$ is used instead of $v_{i}$, when output bridge IZVS occurs, and $i_{L}^{s w}$ differs between $i_{L}(0), i_{L}(\phi), i_{L}(\pi)$ and $i_{L}(\pi+\phi)$ based on which of the four timesteps of the inductor current cycle IZVS occurs. In all IZVS cases, the calculation of $v_{x}$ is made by subtracting from $v_{i / o}$, the drop in voltage over the IGBT in question, during the time $t_{x} . t_{x}$ is the maximum time for voltage to drop to zero over the switch, while achieving CZVS. For input bridge IZVS, this occurs when $i_{L, \min }^{\text {prim }}$ flows through the converter inductance at the switching instant. $t_{x}$ is calculated by balancing the energy stored in the converter inductance at the switching instant with the integral of power discharge from the input bridge through the voltage $v_{o}{ }^{\prime}$. The energy balance is as follows:

$$
\frac{L\left(i_{L, \text { min }}^{\text {prim }}\right)^{2}}{2}=\int_{0}^{t_{x}} v_{o}{ }^{\prime}(t) i_{L}(t) d t=\frac{v_{o}{ }^{\prime} i_{L, \text { min }}^{\text {prim }} t_{x, \text { prim }}}{2}
$$

The premise of this equation is that for CZVS, the energy stored in the converter inductance is completely discharged prior to IGBT turn-on. This is the boundary condition between CZVS and IZVS as within the IZVS region, a portion of this energy will be lost in switching. Solving for $t_{x, \text { prim }}$ :

$$
t_{x, \text { prim }}=2 \sqrt{\frac{n L C v_{i}}{v_{o}}}
$$

The drop in voltage during the time $t_{x}$, (shown in Eqn. 17) is calculated using the standard equation for current through a capacitor, under the assumption of linearly decreasing voltage. Note that the assumption of linearly decreasing voltage implies a minimum rate of decrease of voltage to achieve CZVS, which occurs at the aforementioned boundary condition. Eqn. 17 also assumes that half of the inductor current flows through both of the active bridge switches during an occurrence of IZVS on that bridge. These calculations can also be followed for output bridge IZVS. The complete expression for IZVS loss of a bridge is given by:

$$
P_{s w}^{I Z V S}=4 f\left(E_{\text {on,ref }} \frac{i_{L}^{s w} v_{x}}{v_{r e f} i_{r e f}}+C\left(v_{x}\right)^{2}\right),
$$

HS loss of a bridge is calculated in a similar manner. Analysis of the theoretical current and voltage waveforms associated with the voltage over and current through the DAB IGBTs during turn-on and turn-off, shows that HS power losses occur in relation to snubber capacitance, IGBT turn-on and diode reverse recovery. The occurrence of diode reverse recovery loss is detailed in [12]. These losses are proportional to the full converter input/output voltage, $v$, as opposed to $v_{x}$ which represents a proportion of these voltages. The expressions for snubber capacitance loss [12], IGBT turn-on loss [29] and diode reverse recovery loss [12] are summed and scaled by 
TABLE III

PARAMETERS OF INVERTER, RECTIFIER AND DAB CONVERTER

\begin{tabular}{|c|c|c|}
\hline & Definition & Value (SI Units) \\
\hline$f_{i}$ & Inverter Switching Frequency & $2 \times 10^{4}$ \\
\hline$f_{r}$ & Rectifier Switching Frequency & $2 \times 10^{4}$ \\
\hline$f$ & DAB Switching Frequency & $2 \times 10^{4}$ \\
\hline$L$ & Transformer Leakage Inductance & $8 \times 10^{-6}$ \\
\hline$C$ & DAB Converter Snubber Capacitance & $8 \times 10^{-9}$ \\
\hline$n_{500}$ & Transformer Turns Ratio with $v_{d c}^{r e f}=500 \mathrm{~V}$ & 2.15 \\
\hline$n_{700}$ & Transformer Turns Ratio with $v_{d c}^{r e f}=700 \mathrm{~V}$ & 3.01 \\
\hline$N_{1}$ & Number of Primary Transformer Turns & 10 \\
\hline$R_{p}$ & Transformer Primary Winding Resistance & $1 \times 10^{-2}$ \\
\hline$R_{s}$ & Transformer Secondary Winding Resistance & $2 \times 10^{-2}$ \\
\hline$R_{m}$ & Motor Stator Winding Resistance & 0.04 \\
\hline$R_{g}$ & Generator Stator Winding Resistance & 0.08 \\
\hline$\alpha$ & Transformer Core Loss Parameter & 1 \\
\hline$\beta$ & Transformer Core Loss Parameter & 2.65 \\
\hline$K$ & Transformer Core Loss Parameter & 0.15 \\
\hline$l_{g}$ & Transformer Air Gap Length & $1.5 \times 10^{-3}$ \\
\hline$V_{c}$ & Transformer Core Volume & $3.72 \times 10^{-5}$ \\
\hline$\mu_{0}$ & Permeability of Free Space & $4 \pi \times 10^{-7}$ \\
\hline
\end{tabular}

4 times the switching frequency (as in Eqn. 20) to yield the complete expression for HS loss:

$$
P_{s w}^{H S}=4 f\left(C(v)^{2}+E_{\text {on,ref }} \frac{i_{L}^{s w} v}{v_{r e f} i_{r e f}}+E_{r r, r e f} \frac{v}{v_{r e f}}\right)
$$

$v$ is equal to $v_{i}$ or $v_{o}$, depending on which bridge is in question. The factor of 4 is present because in a given cycle, the occurrence of IZVS/HS implies two IGBTs will both lose energy at two of the four switching intervals. Multiplication by switching frequency gives the energy loss per second, as opposed to energy loss per cycle. Transformer core loss is also included based on the Steinmetz equation given in [12], in which the core loss per unit volume is given as:

$$
P_{\text {core }}^{\text {density }}=K f^{\alpha}\left(B_{p k}\right)^{\beta}
$$

where $B_{p k}$ is the peak swing in flux density about its average value and $K$ and $\alpha$ are Steinmetz Coefficients dependent on the type of material used in the transformer core. Scaling by core volume, the transformer core loss expression can be found. The peak flux density can be approximated by considering the flux associated with an RMS equivalent sinusoidal current waveform. Where $I_{e n c}$ is the current enclosed in the length $l$ over which flux is integrated, Ampère's Law :

$$
\oint B d l=\mu_{0} I_{e n c}
$$

shows the peak flux density is to be equal to the expression in parentheses in the final transformer core loss expression:

$$
P_{\text {core }}=K V_{c} f^{\alpha}\left(\frac{\sqrt{2} \mu_{0} N_{1} i_{L}^{r m s}}{l_{g}}\right)^{\beta}
$$

where the definitions of the various symbols are given in Table III. As will be shown in Section IV, the effect of core loss is negligible. Using the switching loss expressions, conduction loss model, and the transformer loss equation, efficiency maps corresponding to design DC-link voltages of $500 \mathrm{~V}$ and $700 \mathrm{~V}$ are given.

Table I shows IGBT modules chosen from the Infineon range, used in both the primary and secondary bridges of

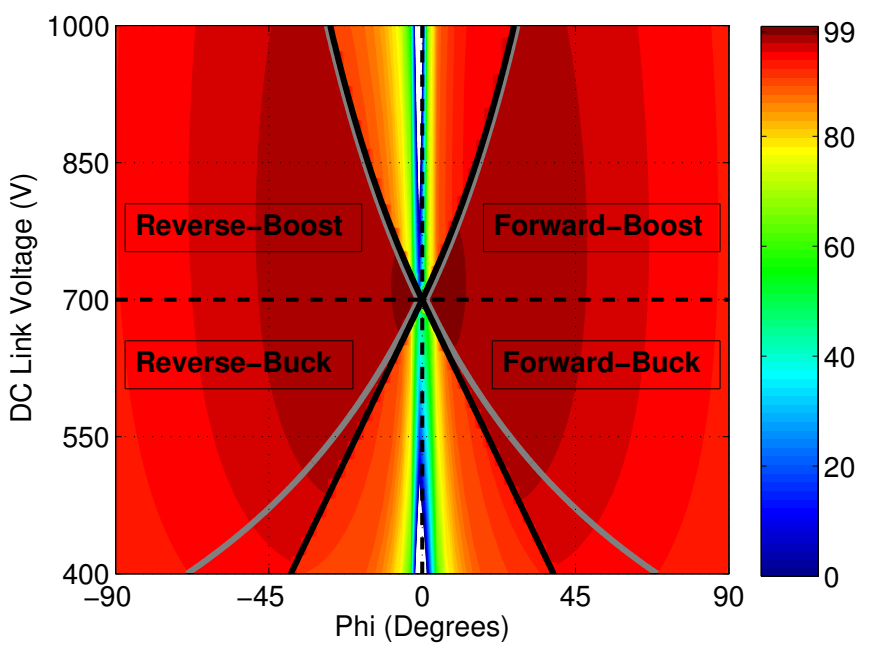

Fig. 9. Efficiency Map of DAB Converter $\left(v_{d c}^{r e f}=700 \mathrm{~V}\right)$. IZVS-HS and CZVS-IZVS operating region boundaries are respectively denoted by bold black and grey lines respectively.

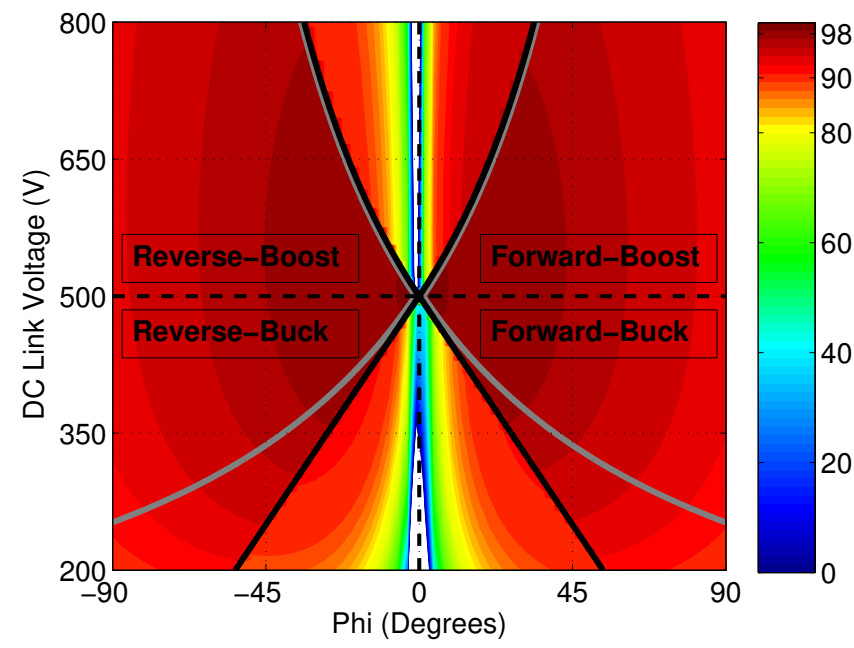

Fig. 10. Efficiency Map of DAB Converter $\left(v_{d c}^{r e f}=500 \mathrm{~V}\right)$. IZVS-HS and CZVS-IZVS operating region boundaries are respectively denoted by bold black and grey lines respectively.

the DAB converter for design DC-link voltages of $400 \mathrm{~V}$ to $1200 \mathrm{~V}$ in $100 \mathrm{~V}$ increments. Modules are selected based on switched voltage, and are capable of conducting worst case RMS, average and peak current in all operating conditions (assuming $\max |\phi|=90^{\circ}$ ). For each design voltage, the turns ratio is selected to be the ratio of the DC-link voltage to the open circuit battery voltage, as indicated in Table III, to achieve $d=1$ when the DC-link voltage is equal to the design value. As shown in [34], this results in avoidance of converter HS. This will be clear from Fig. 22 in Section IV, and agrees with Table II. The efficiency maps for the $700 \mathrm{~V}$ and $500 \mathrm{~V}$ designs are shown in Figs. 9 and 10. Operating modes corresponding to each $\phi-v_{o}$ quadrant are labeled. 


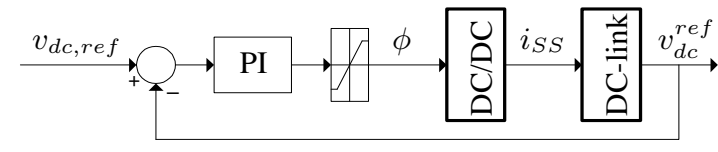

Fig. 11. Block diagram showing the CVPI control.

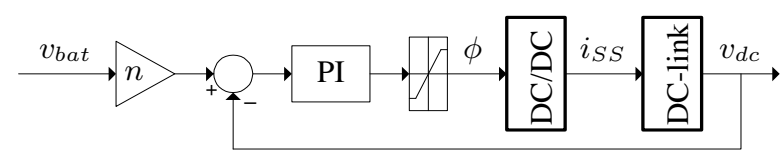

Fig. 12. Block diagram showing the URPI control.

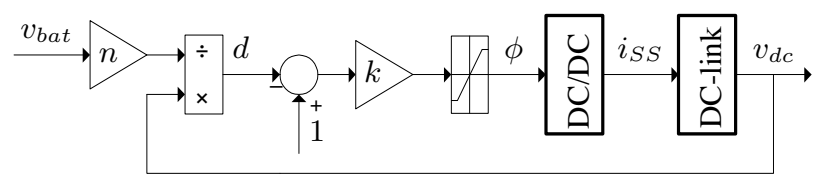

Fig. 13. Block diagram showing the PZVS control.

\section{Control of DC-Link Voltage}

This Section details the four control schemes tested within the paper, including parameter values obtained through trial and error tuning.

\section{A. Constant Voltage PI Control}

Two CVPI schemes are tested. These schemes represent the conventional approach of DC-link voltage control. They respectively control the DC-link voltage to $700 \mathrm{~V}$ (as in [21]) and $500 \mathrm{~V}$, following the analysis in Section II-B. Both schemes are represented by Fig. 11, and $K_{p}=0.16$ and $K_{i}=0.016$ are used in this work.

1) CVPI $700 \mathrm{~V}$ : The input of the existing PI control scheme is the error between a constant $700 \mathrm{~V}$ reference and the measured DC-link voltage. This scheme manipulates the phase shift between the gating signals of the primary and secondary bridges of the DC/DC converter, which has the effect of controlling the power (by Eqn. 9) from the DAB converter such that a DC-link voltage of $700 \mathrm{~V}$ is maintained in steady state, regardless of the battery voltage.

2) CVPI $500 \mathrm{~V}:$ A $500 \mathrm{~V}$ CVPI scheme is also tested, in order to provide a benchmark for performance of the following two variable voltage schemes which entail designing about a reference of $500 \mathrm{~V}$. This voltage value was found to be a suitable one to minimize the losses in the inverter and rectifier, as explained in Section II-B.

\section{B. Unity Ratio PI Control}

Based on the premise that DAB HS does not occur when $d=1$, a URPI control scheme is implemented with the goal of achieving unity voltage conversion ratio throughout the tested drive cycles. This scheme is shown in Fig. 12. The battery voltage rises/falls while charging/discharging. The aim of this scheme is to vary the DC-link voltage in proportion to the variation of battery voltage. As with the previous control, the output of the implemented PI controller is $\phi$. However, the input is the error between the desired and instantaneous DC-link voltage. This control is tested for a powertrain designed for $500 \mathrm{~V}$ DC-link voltage, therefore simultaneously attempting to achieve efficiency enhancement of the inverter and rectifier through increased modulation indices compared to the previous level of control. $K_{p}=0.1$ and $K_{i}=0.01$ are used in this work.

\section{Persistent Zero Voltage Switching Control}

In order to provide a more deterministic relationship between $d$ and $\phi$ that prevents DAB converter HS operation, the proportional control law

$$
\phi=k(1-d),
$$

also shown in Fig. 13, is implemented. In this case also, the powertrain uses converters designed for a DC-link voltage of $500 \mathrm{~V} . k$ is a defined constant, such that:

$$
-\frac{2}{\pi} \leq \frac{1}{k} \leq \frac{2}{\pi}
$$

The inequality constraints given in Eqn. 26 are acquired from the expressions in Table II to restrict operation in the ZVS region. The reasoning behind the scheme is twofold. Firstly, due to the relationship between DAB power flow and DC-link voltage, operating points in the Forward-Buck and ReverseBoost regions tend towards the point $(\phi, d)=(0,1)$, yielding a stable controller. Operating in these two regions only (instead of all four quadrants which Eqn. 26 is valid for) further limits the value of $k$, which is finally given by:

$$
k \geq \frac{\pi}{2}
$$

Secondly, the memoryless nature of the controller means that HS never occurs during operation, even very near the origin $(\phi, d)=(0,1)$ where even a very small overshoot, likely to be experienced by other control schemes, would be detrimental for the efficiency. The superiority of this Persistent Zero Voltage Switching (PZVS) scheme will be demonstrated by comparing its performance with that of both CVPI schemes and the URPI scheme. As with the previous controllers, the manipulated variable of the controller is $\phi$. In order to simultaneously avoid HS and operation close to the boundaries of the regions of interest, $k=10$ has been chosen in this work.

\section{Simulation Results}

The two drive cycles tested in this paper are the New York City Cycle (NYCC) and the Highway Fuel Economy Test (HWFET). Regardless of the DC-link voltage, the torquespeed operating locus of the PMSM for a respective drive cycle does not change, as it is only dependent on the road load. The NYCC and HWFET loci of PMSM operation are superimposed onto the inverter efficiency maps corresponding to DC-link $700 \mathrm{~V}$ and $500 \mathrm{~V}$ designs in Figs. 14-17. Similarly, the operating loci of the PMSG are superimposed onto the $700 \mathrm{~V}$ and $500 \mathrm{~V}$ rectifier efficiency maps in Figs. 18-21. Although during operation the engine operating point is fixed, the loci show engine turn off and turn on also. Note that for both the NYCC and HWFET, for the $500 \mathrm{~V}$ design, both the 


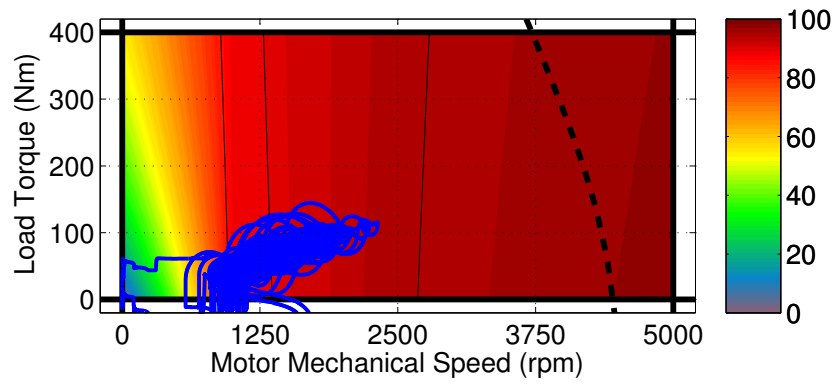

Fig. 14. HWFET Inverter Simulation Results $\left(v_{d c}^{r e f}=700 \mathrm{~V}\right)$.

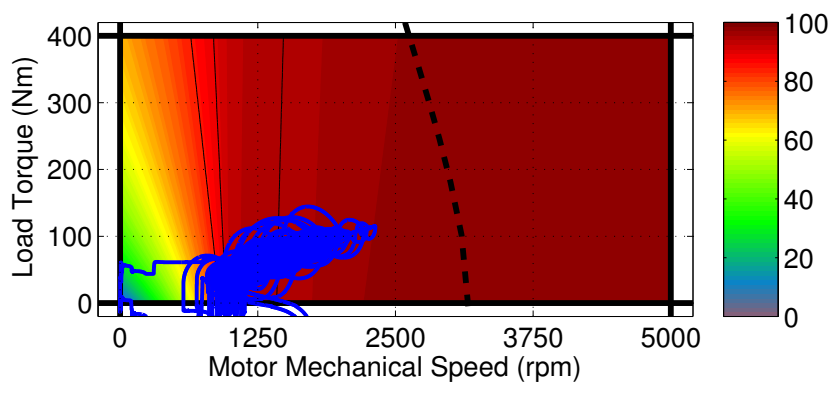

Fig. 15. HWFET Inverter Simulation Results $\left(v_{d c}^{r e f}=500 \mathrm{~V}\right)$.

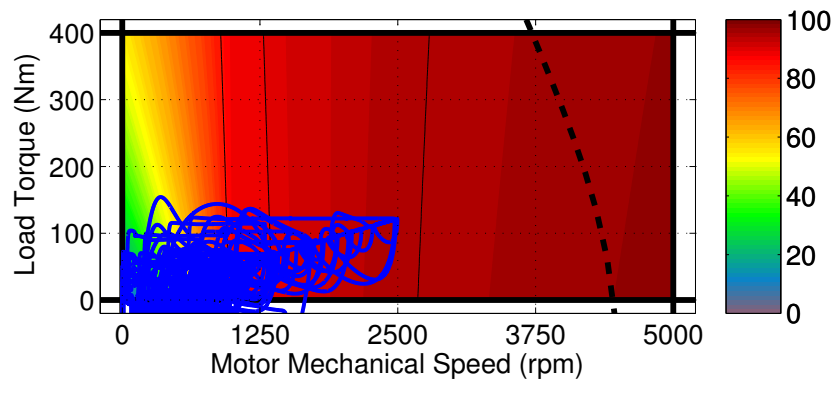

Fig. 16. NYCC Inverter Simulation Results $\left(v_{d c}^{r e f}=700 \mathrm{~V}\right)$.

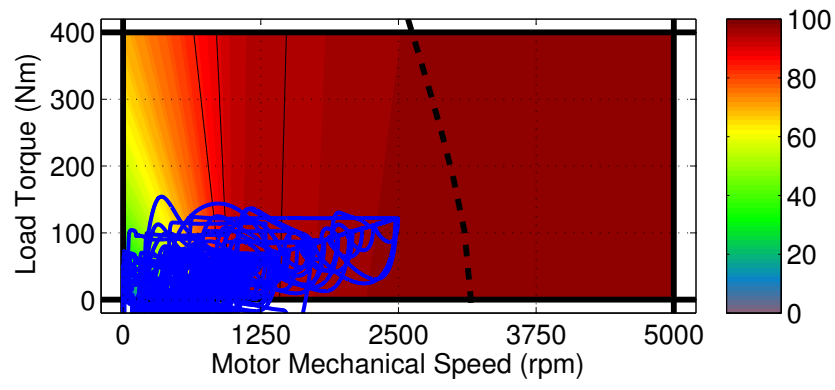

Fig. 17. NYCC Inverter Simulation Results $\left(v_{d c}^{r e f}=500 \mathrm{~V}\right)$.

rectifier and inverter experience higher efficiency throughout the entire cycles compared to the $700 \mathrm{~V}$ case. However, operation of both converters is closer to the linear modulation constraint, implying higher modulation indices. As constant DC-link voltage is assumed in these plots, these results do not guarantee that overmodulation will not occur for the variable voltage URPI and PZVS control schemes.

Fig. 22 shows the DAB DC/DC converter operating loci

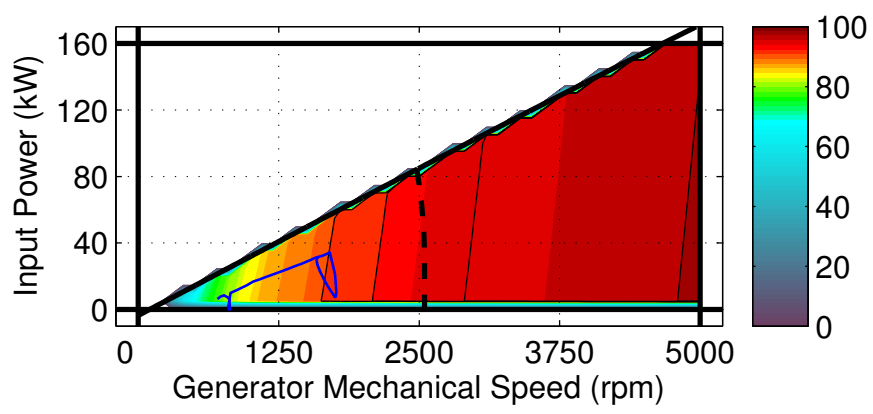

Fig. 18. HWFET Rectifier Simulation $\left(v_{d c}^{r e f}=700 \mathrm{~V}\right)$.

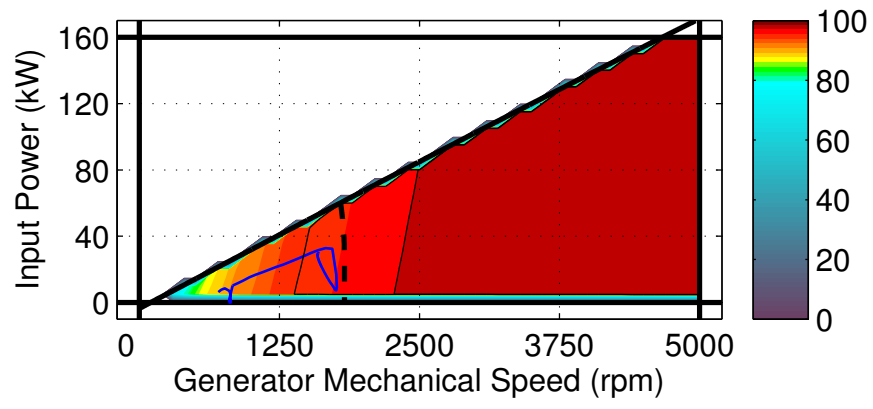

Fig. 19. HWFET Rectifier Simulation $\left(v_{d c}^{r e f}=500 \mathrm{~V}\right)$.

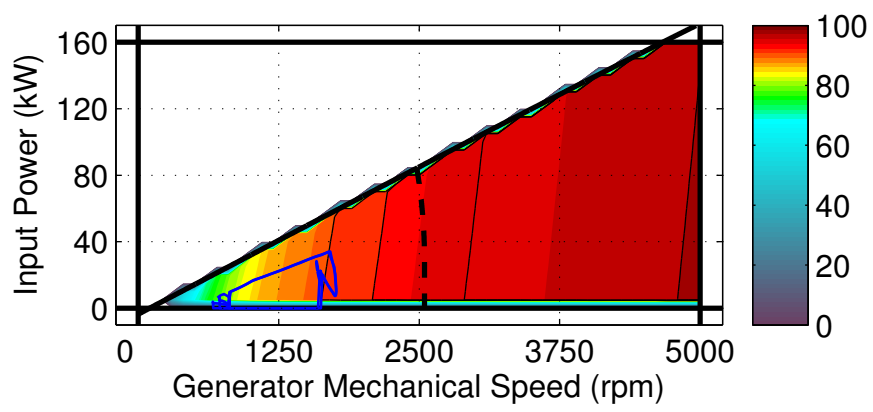

Fig. 20. NYCC Rectifier Simulation $\left(v_{d c}^{r e f}=700 \mathrm{~V}\right)$.

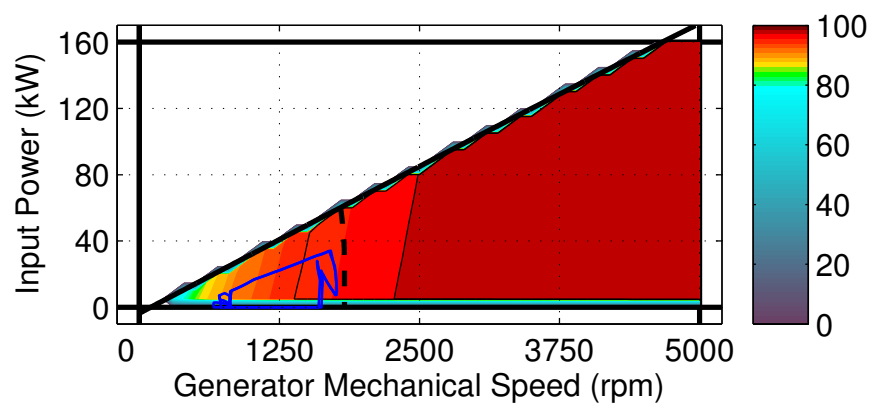

Fig. 21. NYCC Rectifier Simulation $\left(v_{d c}^{r e f}=500 \mathrm{~V}\right)$.

for the four control schemes studied in this work, for the NYCC. In the case of the HWFET, the types of switching (i.e. CZVS, IZVS, HS) which respectively correspond to each of the four control schemes, are the same as those which occur for the NYCC, although the extent of occurrences vary. The bold black lines are the IZVS-HS boundaries as given in Figs. 


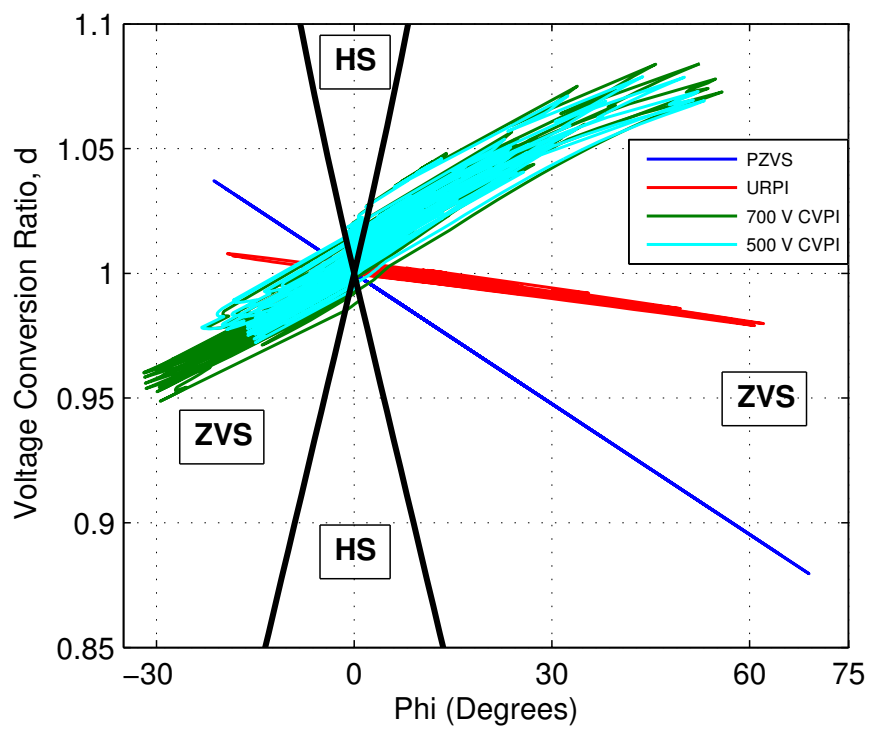

Fig. 22. DAB DC/DC converter loci on the $\phi-d$ plane for the NYCC drive cycle for four DC-link control schemes.

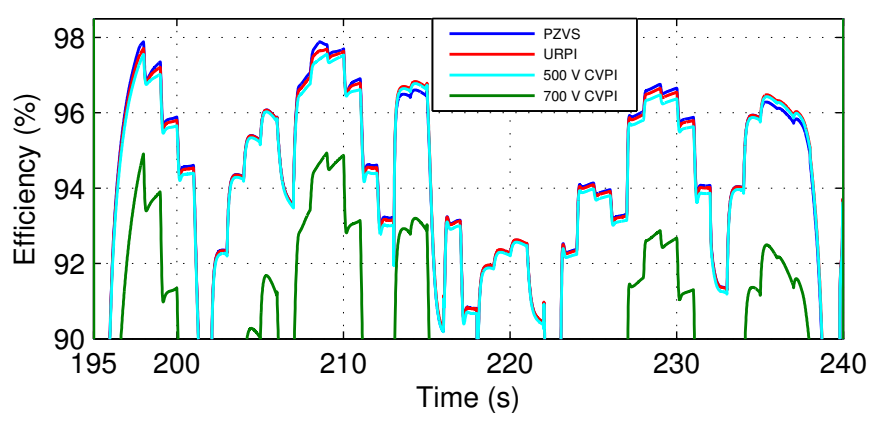

Fig. 23. Inverter efficiency for a window of NYCC for four control schemes.

9 and 10. The IZVS region is close to the border of the ZVS region, although the CZVS-IZVS boundaries are not shown as they change dynamically with system operating variables. From Fig. 22, it is clear that both of the CVPI schemes result in HS of the DAB converter. Although $d=1$ is desirable, the URPI control scheme implemented in an attempt to achieve this goal also results in HS. Although the desired DC-link voltage is known at any given time by the URPI controller, it is unable to instantaneously achieve this voltage. This is due to the integral time lag which causes the operating point of the converter to cross the boundary into loss regions at low power. In contrast, the PZVS control law implemented avoids HS throughout both drive cycles, transitioning from ForwardBuck and Reverse-Boost operating modes directly through the $(\phi, d)=(0,1)$ point. This results in high efficiency operation of the DAB converter, by varying the DC-link voltage.

Fig. 23 shows the variation of inverter efficiency for each of the control schemes, simulated on the NYCC cycle. Rectifier efficiencies are not plotted, as the rectifier is mostly inactive for the NYCC. As indicated by the previous efficiency maps, the inverter efficiency corresponding to the $700 \mathrm{~V}$ CVPI

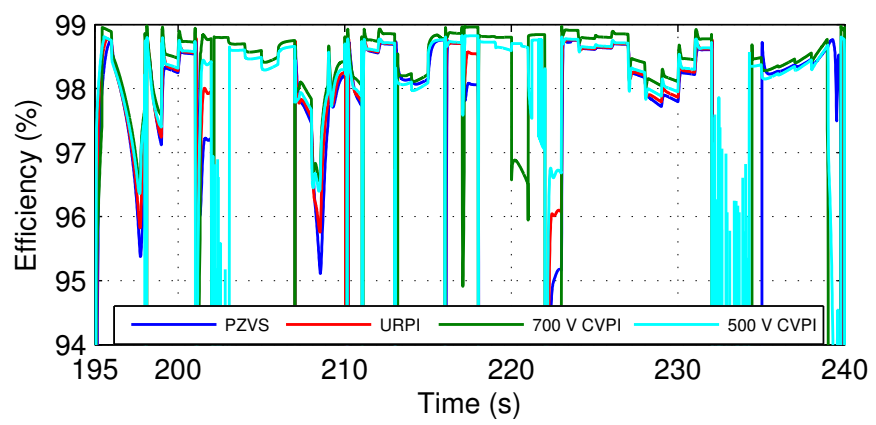

Fig. 24. DC/DC converter efficiency for a window of NYCC for four control schemes.

TABLE IV

DAB LOSS BREAKDOWN, NYCC PZVS

\begin{tabular}{|c|c|c|c|}
\hline $\begin{array}{c}\text { Operating } \\
\text { Mode }\end{array}$ & Bridge & IZVS Loss (kJ) & $\begin{array}{c}\text { \% Time } \\
\text { in IZVS }\end{array}$ \\
\hline Forward Buck & Input & 6.42 & 43.89 \\
\hline Reverse Boost & Input & 25.14 & 31.25 \\
\hline Forward Buck & Output & 35.46 & 47.50 \\
\hline Reverse Boost & Output & 5.64 & 30.97 \\
\hline
\end{tabular}

scheme is lower than those corresponding to the other schemes designed about $500 \mathrm{~V}$. However, the inverter efficiency plots all follow a similar pattern dictated by the speed and torque of the PMSM which also determine the three-phase voltage level of the inverter. As the operating point of the engine is mostly fixed when operating a series HEV with a Thermostat SCS, variation of rectifier efficiency is dictated by variation of DC-link voltage. This is the primary reason as to why within the following results, the PZVS scheme is seen to yield better results for the NYCC as opposed to the HWFET, when compared to the other schemes. For HWFET, the PZVS scheme causes high DC link voltage while the battery is recharging, whereas the engine rarely provides power during the NYCC, as the battery does not discharge fully during this drive cycle.

Similarly, Fig. 24 shows the variation of DAB converter efficiency for each of the control schemes, simulated on the NYCC drive cycle. However, a significant insight cannot be garnered from this plot. Efficiencies of $98 \%$ to $99 \%$ are achievable within the CZVS region with all schemes. However, at times, efficiency also drops substantially for each of the schemes. For the CVPI and URPI schemes this is often related to HS. For PZVS, this is due to the occurrence of IZVS when power demand is very low. The associated losses differ significantly. Therefore without simultaneously showing the power demand, analyzing this efficiency plot will provide no information relating to the associated levels of losses and hence the overall powertrain efficiency.

Tables IV, V and VI give a better understanding of the effectiveness of the PZVS, URPI and 500 V CVPI schemes, by presenting detailed DAB loss information. The percentage of the drive cycle spent within each IZVS and HS region of the $\phi-d$ plane is also provided. The following conclusions can be drawn from this information. Although HS is avoided when using the PZVS scheme, IZVS occurs on both the input 
TABLE $\mathrm{V}$

DAB LOSS BREAKDOWN, NYCC URPI

\begin{tabular}{|c|c|c|c|c|c|}
\hline $\begin{array}{c}\text { Operating } \\
\text { Mode }\end{array}$ & Bridge & $\begin{array}{c}\text { IZVS } \\
\text { Loss }(\mathrm{kJ})\end{array}$ & $\begin{array}{c}\text { HS Loss } \\
(\mathrm{kJ})\end{array}$ & $\begin{array}{c}\text { \% Time } \\
\text { in IZVS }\end{array}$ & $\begin{array}{c}\text { \% Time } \\
\text { in HS }\end{array}$ \\
\hline Forward Buck & Input & 0.86 & 0.00 & 8.87 & 0.00 \\
\hline Forward Boost & Input & 5.79 & 0.6 & 36.05 & 0.22 \\
\hline Reverse Buck & Input & 0.00 & 0.00 & 0.01 & 0.00 \\
\hline Reverse Boost & Input & 147.40 & 0.00 & 33.01 & 0.00 \\
\hline Forward Buck & Output & 5.00 & 0.00 & 9.07 & 0.00 \\
\hline Forward Boost & Output & 29.02 & 0.00 & 36.24 & 0.00 \\
\hline Reverse Buck & Output & 0.00 & 0.00 & 0.01 & 0.00 \\
\hline Reverse Boost & Output & 1.87 & 4.06 & 11.47 & 21.52 \\
\hline
\end{tabular}

TABLE VI

DAB LOSS BREAKDOWN, NYCC CVPI $500 \mathrm{~V}$

\begin{tabular}{|c|c|c|c|c|c|}
\hline $\begin{array}{c}\text { Operating } \\
\text { Mode }\end{array}$ & Bridge & $\begin{array}{c}\text { IZVS } \\
\text { Loss }(\mathrm{kJ})\end{array}$ & $\begin{array}{c}\text { HS Loss } \\
(\mathrm{kJ})\end{array}$ & $\begin{array}{c}\text { \% Time } \\
\text { in IZVS }\end{array}$ & $\begin{array}{c}\text { \% Time } \\
\text { in HS }\end{array}$ \\
\hline Forward Buck & Input & 0.86 & 0.00 & 5.76 & 0.00 \\
\hline Forward Boost & Input & 1.85 & 60.43 & 20.04 & 21.59 \\
\hline Reverse Buck & Input & 0.09 & 0.37 & 4.08 & 0.13 \\
\hline Reverse Boost & Input & 40.44 & 0.00 & 17.76 & 0.00 \\
\hline Forward Buck & Output & 4.35 & 6.75 & 4.72 & 1.03 \\
\hline Forward Boost & Output & 23.01 & 0.00 & 35.18 & 0.00 \\
\hline Reverse Buck & Output & 1.52 & 0.00 & 5.19 & 0.00 \\
\hline Reverse Boost & Output & 1.19 & 0.83 & 11.94 & 5.80 \\
\hline
\end{tabular}

and output bridge of the converter for a significant percentage of the NYCC. The losses remain relatively low as this IZVS only occurs at low power, very close to the $(\phi, d)=(0,1)$ point. As the scheme is confined to operate in two quadrants of the $\phi-d$ plane, it has only two operating modes. As Fig. 22 suggests, for the URPI scheme, the operating point strays into the HS region for boost operation. However, input bridge IZVS during Reverse-Boost operation is responsible for the majority of DAB losses. Although the input bridge spends a comparable amount of time operating within the IZVS region of the Forward-Boost quadrant, the resulting losses are lower due to the corresponding power demand of the DAB converter. Although it is clear from Fig. 22 that the 500 V CVPI scheme yields CZVS at high power, this can be said for each of the schemes. The occurrence of HS is clear at low power during boost operation. $60.43 \mathrm{~kJ}$ of energy is lost in the input bridge during Forward-Boost HS. Efficiency plummets during this period of operation.

Figs. 25 and 26 respectively show converter modulation indices for NYCC and HWFET, corresponding to the PZVS

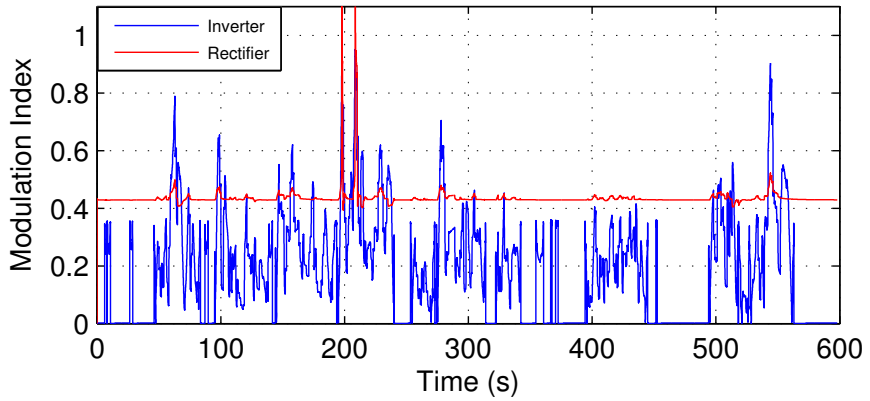

Fig. 25. Inverter and rectifier modulation indices when NYCC is simulated.

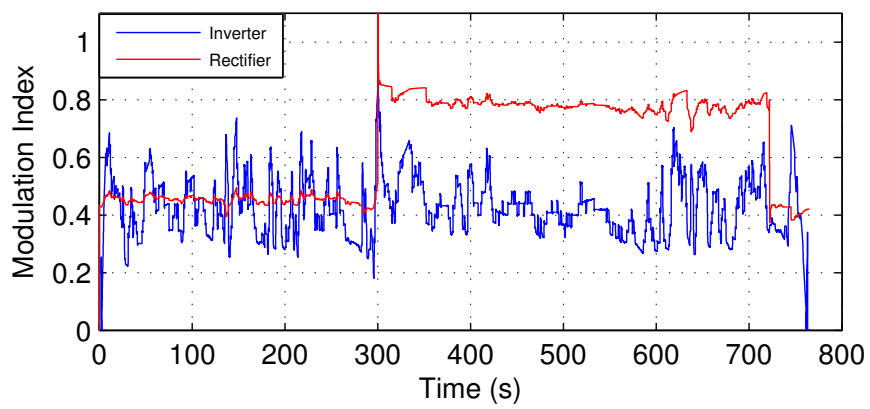

Fig. 26. Inverter and rectifier modulation indices when HWFET is simulated.

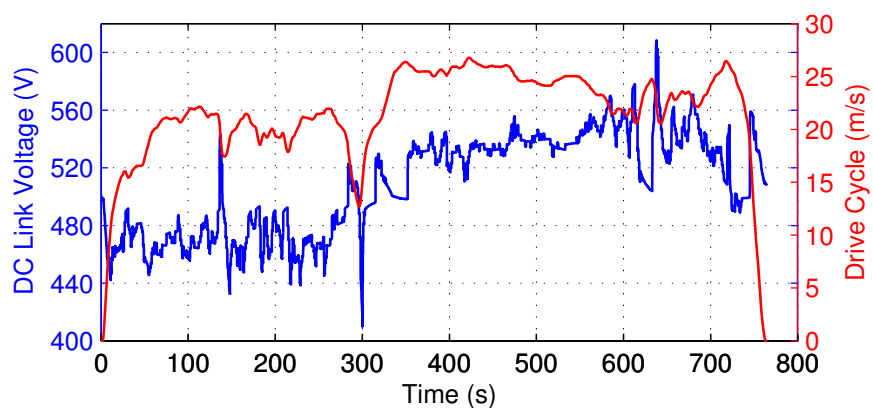

Fig. 27. DC-link voltage and NYCC speed profile.

scheme. In both cases, overmodulation of the inverter never occurs over a sustained period. Transient overmodulation occurs briefly within the rectifier for both drive cycles. During transient periods (such as engine turn on), the direct axis PMSG current deviates from its desired value of $0 \mathrm{~A}$. This value is quickly achieved after this transient thanks to the integral action of the PMSG PI control. However, the rectifier efficiency plots both assume constant direct axis current of $0 \mathrm{~A}$. Therefore, the operating point strays into the region of overmodulation briefly during harsh transients. Due to the fact that the level of overmodulation is so slight, and occurrence rare, the loss expressions given in Eqns. 3 and 4 are assumed to be accurate.

Figs. 27 and 28 show the variation of DC-link voltage caused by the PZVS scheme for the NYCC and HWFET respectively. The drive cycles themselves are also shown. Although, the converters have been designed for a DC-link voltage of $500 \mathrm{~V}$, the switches chosen can endure up to 650

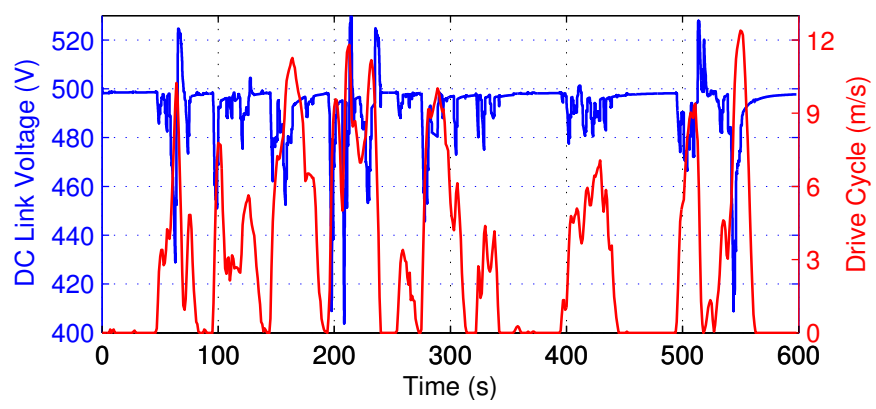

Fig. 28. DC-link voltage and HWFET speed profile. 
$\mathrm{V}$; see Table I. As shown, this maximum voltage is never exceeded for either of the drive cycles. Fig. 28 can be used to explain the voltage variation most effectively. The battery SOC falls to $50 \%$ SOC at $300 \mathrm{~s}$. The engine turns on and supplies until SOC of $80 \%$ is reached at $700 \mathrm{~s}$. The opencircuit battery voltage is approximately $232 \mathrm{~V}$ in the typical SOC range of operation. While charging, this voltage increases and while discharging it decreases. This is reflected in the DClink voltage. As shown, when the battery is charging in the $300-700 \mathrm{~s}$ interval, the DC-link voltage is above its design value, and while discharging the DC-link voltage drops below its design value. As $d$ is not controlled to a constant value, the variation of battery and DC-link voltage is not a constant relationship, but rather is a function of $\phi$. The same applies to the NYCC in Fig. 27, but occurs at a more sporadic rate.

Figs. 29 and 30 compare the power electronic energy loss data of each scheme, for the NYCC and HWFET respectively. Rectifier losses for the NYCC are almost zero as the engine very rarely supplies during the cycle. This is not the case for the HWFET. It is clear that power loss is dominated by switching for the inverter and rectifier. By comparing the switching losses of the inverter and rectifier (for HWFET) respectively for the $700 \mathrm{~V}$ CVPI scheme and the $500 \mathrm{~V}$ CVPI scheme, the benefit of designing about a lower voltage is clear. As the DC-link voltage varies with the movement of the DAB operating point, for the variable voltage schemes the rectifier and inverter switching losses are dependent on the proportion of battery charging and discharging associated with the control schemes. As the battery discharges during the NYCC, DC-link voltage is lower than the design value of $500 \mathrm{~V}$ and hence inverter efficiency is higher compared to the $500 \mathrm{~V}$ CVPI simulation. However, the battery charges from 300s to 700 s of the HWFET, and therefore the DC-link voltage is above 500 $\mathrm{V}$ and as a result, the inverter is less efficiency for the PZVS scheme as for $500 \mathrm{~V} \mathrm{CVPI}$ control. This is not surprising, as the primary design goal of the PZVS scheme was to lower DAB switching losses. Although the PZVS scheme achieves this goal for both drive cycles, the energy saving is offset by an increase in rectifier switching losses in the case of the HWFET. For a given engine power rating, this indicates that the energy savings offered by the PZVS scheme increase with the energy storage capability of the HEV battery. By comparing the DAB switching losses corresponding to URPI and PZVS, the superiority of the latter scheme can be quantified. For both drive cycles, the URPI scheme does not deliver the expected powertrain energy savings due to excessive IZVS on the input bridge during reverse boost operation. Core loss is clearly negligible. Also, conduction losses are relatively low in all converters. This loss is related to the level of current flowing through each of the converters in order to satisfy the PMSM load which is dependent on the drive cycle. For the NYCC, the order of performance of the schemes (in order of increasing total powertrain energy loss) is as follows: PZVS, $500 \mathrm{~V} \mathrm{PI}$, URPI, $700 \mathrm{~V}$ PI. For the NYCC, the percentage energy saving achieved by the PZVS scheme compared with the original $700 \mathrm{~V}$ PI scheme is $52.5 \%$. For the HWFET, the overall performance of the PZVS, URPI and 500 V CVPI schemes are roughly equivalent.

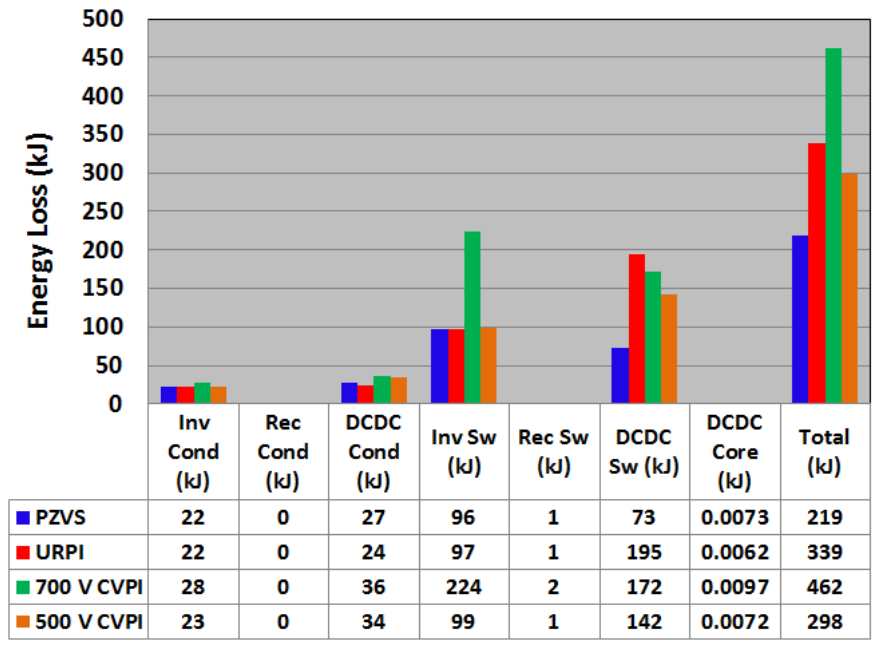

Fig. 29. Converter energy loss data by implemented control for the NYCC.

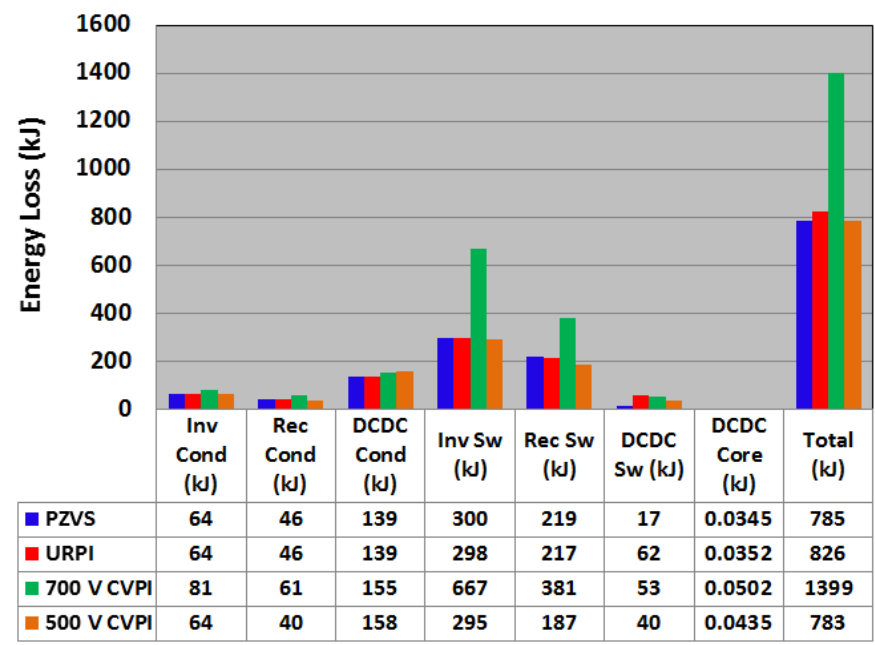

Fig. 30. Converter energy loss data by implemented control for the HWFET.

\section{CONClusion}

The DC-link voltage in a series HEV imposes a constraint in relation to the feasible operating region of the PMSM and PMSG, corresponding to unity modulation index. However, it also offers possibilities for improving the overall efficiency of the power electronics in the powertrain. The efficiency of the inverter and rectifier are maximized by increasing modulation indices as close as possible to unity (corresponding to a drop in DC-link voltage). The losses of the inverter and rectifier are dominated by switching. Therefore, efficiency is increased by dropping the switching voltage. Switching losses of the DAB converter vary between CZVS (zero loss), IZVS (low loss) and HS (high loss). DAB conduction losses are reduced by keeping power flow (and therefore $\phi$ ) low. Switching losses are dependent on the relationship between the voltage conversion ratio and $\phi$. By manipulating $\phi$, the DC-link voltage can be controlled in such a way that maximizes the occurrence of lossless switching within the DAB converter. This PZVS control scheme is the most desirable scheme tested for the NYCC as power electronic loss was minimized, compared 
to the other control schemes tested. Such benefits were not found for the HWFET simulation, due to the higher rectifier switching losses which occur during battery recharging. The results indicate that the PZVS control is most useful for vehicles with high hybridization factor, for application in an urban environment.

\section{REFERENCES}

[1] O. Edenhofer et al., "Climate change 2014: Mitigation of climate change," IPCC, Sci. Rep., 2014.

[2] B. K. Bose, "Global energy scenario and impact of power electronics in 21st century," IEEE Transactions on Industrial Electronics, vol. 60, pp. 2638-2651, July 2013.

[3] A. Khaligh, A. M. Rahimi, and A. Emadi, "Modified pulse-adjustment technique to control $\mathrm{dc} / \mathrm{dc}$ converters driving variable constant-power loads," Industrial Electronics, IEEE Transactions on, vol. 55, no. 3, pp. 1133-1146, 2008.

[4] S. G. Wirasingha and A. Emadi, "Classification and review of control strategies for plug-in hybrid electric vehicles," Vehicular Technology, IEEE Transactions on, vol. 60, no. 1, pp. 111-122, 2011.

[5] C. Mi, M. A. Masrur, and D. W. Gao, Hybrid Electric Vehicles: Principles and Applications with Practical Perspectives. John Wiley \& Sons, 2011.

[6] J. O. Estima and A. J. M. Cardoso, "Efficiency analysis of drive train topologies applied to electric/hybrid vehicles," IEEE Transactions on Vehicular Technology, vol. 61, pp. 1021-1031, March 2012.

[7] J. Saravanan and S. S. Elsi, "Zero voltage switching of boost converter with high voltage gain," Int. Journal of Engineering Research and Applications, vol. III, Nov-Dec 2013.

[8] S. Dusmez, A. Hasanzadeh, and A. Khaligh, "Loss analysis of nonisolated bidirectional dc/dc converters for hybrid energy storage system in evs," in Industrial Electronics (ISIE), 2014 IEEE 23rd International Symposium on. IEEE, 2014, pp. 543-549.

[9] R. T. Naayagi, A. J. Forsyth, and R. Shuttleworth, "High-power bidirectional DCDC converter for aerospace applications," IEEE Transactions on Power Electronics, vol. 27, Nov 2012.

[10] R. T. Naayagi and A. J. Forsyth, "Bidirectional DC-DC converter for aircraft electric energy storage systems," in 5th IET International Conference on Power Electronics Machines and Drives (PEMD 2010), 2010, pp. 1-6.

[11] F. Krismer and J. Kolar, "Efficiency-optimized high-current dual active bridge converter for automotive applications," IEEE Transactions on Industrial Electronics, vol. 59, pp. 2745-2760, 2012.

[12] S. Inoue and H. Akagi, "A bidirectional DC-DC converter for an energy storage system with galvanic isolation," IEEE Transactions on Power Electronics, vol. 22, pp. 2299-2305, 2007.

[13] H. Li, F. Z. Peng, and J. Lawler, "A natural ZVS medium-power bidirectional DC-DC converter with minimum number of devices," IEEE Transactions on Inductry Applications, vol. 39, 2003.

[14] V. Beldjajev and I. Roasto, "Dual active bridge based isolation stage for power electronic transformer," Power Electronics, Electrical Drives, Automation and Motion (SPEEDAM), pp. 216-219, 2012.

[15] A. K. Rathore and U. Prasanna, "Analysis, design, and experimental results of novel snubberless bidirectional naturally clamped zcs/zvs current-fed half-bridge dc/dc converter for fuel cell vehicles," Industrial Electronics, IEEE Transactions on, vol. 60, no. 10, pp. 4482-4491, 2013.

[16] H. Al-Sheikh, O. Bennouna, G. Hoblos, and N. Moubayed, "Modeling, design and fault analysis of bidirectional dc-dc converter for hybrid electric vehicles," in Industrial Electronics (ISIE), 2014 IEEE 23rd International Symposium on. IEEE, 2014, pp. 1689-1695.

[17] H. Karshenas, H. Daneshpajooh, A. Safaee, P. Jain, and A. Bakhshai, Energy Storage in the Emerging Era of Smart Grids. Intech, 2011, ch. 8, pp. 161-178. [Online]. Available: http://cdn.intechopen.com/pdfswm/20368.pdf

[18] Z. Amjadi and S. S. Williamson, "Power-electronics-based solutions for plug-in hybrid electric vehicle energy storage and management systems," Industrial Electronics, IEEE Transactions on, vol. 57, no. 2, pp. 608616, 2010

[19] M. B. Camara, H. Gualous, F. Gustin, A. Berthon, and B. Dakyo, "Dc/dc converter design for supercapacitor and battery power management in hybrid vehicle applicationspolynomial control strategy," Industrial Electronics, IEEE Transactions on, vol. 57, no. 2, pp. 587-597, 2010.
[20] Y. Song and B. Wang, "Evaluation methodology and control strategies for improving reliability of hev power electronic system," Vehicular Technology, IEEE Transactions on, vol. 63, no. 8, pp. 3661-3676, 2014.

[21] A. Shukla, "Modelling and simulation of hybrid electric vehicles," Ph.D. dissertation, Imperial College London, 2012.

[22] S. A. Evangelou and A. Shukla, "Advances in the modelling and control of series hybrid electric vehicles," in Proceedings of 2012 American Control Conference. Montreal, Canada: IEEE, 27-29 June 2012.

[23] M. Ehsani, Y. Gao, and A. Emadi, Modern electric, hybrid electric, and fuel cell vehicles: fundamentals, theory, and design. CRC Press, 2010.

[24] Y. Ko, J. Lee, and H. Lee, "A supervisory control algorithm for a series hybrid vehicle with multiple energy sources," Vehicular Technology, IEEE Transactions on, vol. 64, no. 11, pp. 4942-4953, 2015.

[25] W. Shabbir and S. A. Evangelou, "Efficiency maximizing and charge sustaining supervisory control for series hybrid electric vehicles," in Proc. IEEE Annual Conference on Decision and Control Systems, Maui, HI, dec 2012, pp. 6327-6332.

[26] "ON semiconductor's motor control IGBTs and free-wheeling diodes," ON Semiconductor, Tech. Rep., 2012.

[27] N. Mohan, T. Undeland, and W. Robbins, Power Electronics: Converters, Applications and Design. John Wiley and Sons, 2003.

[28] D. Graovac and M. Purschel, "IGBT power losses calculations using data-sheet parameters," Infineon Technologies, Tech. Rep., 2009.

[29] M. H. Bierhoff and F. W. Fuchs, "Semiconductor losses in voltage source and current source IGBT converters based on analytical derivation," in Power Electronics Specialists Conference (PESC 04), IEEE 35th Annual, vol. 4, 2004, pp. 2836-2842.

[30] G. T. R. Das and V. Subrahmanyam, "Evaluation of control methods for permanent magnet synchronous motors," in IEEE Proceedings of International Conference on Power Electronics and Drive Systems. IEEE, 1995, pp. 303-308.

[31] M. Moussa, A. Helal, Y. Gaber, and H. Youssef, "Unity power factor control of permanent magnet motor drive system," in Power System Conference, 2008. MEPCON 2008. 12th International Middle-East. IEEE, 2008, pp. 360-367.

[32] "AFM-140 axial flux motor," EVO Electric Ltd., 2010. [Online]. Available: http://www.evo-electric.com/inc/files/AFM-140-Spec-SheetV1.1.pdf

[33] "AFG-140 axial flux generator," EVO Electric Ltd., 2010. [Online]. Available: http://www.evo-electric.com/inc/files/AFG-140-Spec-SheetV1.1.pdf

[34] M. Kheraluwala, R. Gascoigne, D. Divan, and E. Baumann, "Performance characterization of a high power dual active bridge DC-DC converter," IEEE Transactions on Industry Applications, vol. 28, pp. 1294-1301, 1992.

[35] R. Seyezhai, "Performance evaluation of modulation strategies for dual active bridge multiport DC-DC converters," IOSR Journal of Engineering, vol. I, pp. 077-083, 2011.

[36] A. Rathore and P. Xuewei, "Novel bidirectional snubberless naturally commutated soft-switching current-fed full-bridge isolated dc/dc converter for fuel cell vehicles," Industrial Electronics, IEEE Transactions on, vol. 61, no. 5, pp. 2307-2315, 2014.

[37] Y. H. Abraham, W. Xiao, H. Wen, and V. Khadkikar, "Estimating power losses in dual active bridge DC-DC converter," Electric Power and Energy Conversion Systems (EPECS), pp. 1-5, 2011.

[38] C. Nan, "Dual active bridge converter with PWM control in solid state transformer application,” Master's thesis, Arizona State University, 2012.

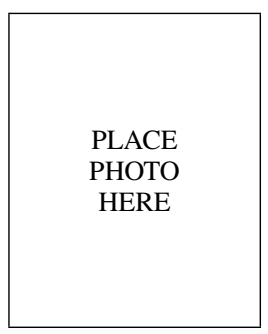

Mark Roche is originally from Kilkenny, Ireland. $\mathrm{He}$ received the B.Eng. degree in energy engineering from University College Cork, Ireland in 2014. He was named 'Engineering Graduate of the Year (Cork Region)' by Engineers Ireland for performance in this degree. In 2015, he received the M.Sc. degree in control systems from Imperial College London. Upon completion of the degree, he was awarded the 'Control Systems Outstanding Achievement Prize'. He joined Jaguar Land Rover in 2015, where he works as a model-based software developer for the vehicle supervisory controller. He is a member of the IET. 


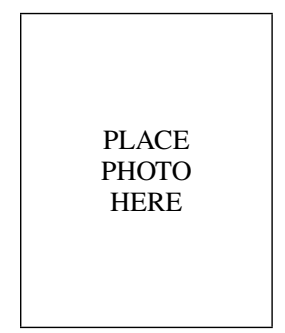

Wassif Shabbir received the M.Eng. degree in electrical and electronic engineering from Imperial College London in 2011, and the Ph.D. degree from the same department in 2016. His research interests include modeling, control and optimization of hybrid electric vehicles. He became a Member of the IEEE in 2011 and a Member of the IET in 2008.

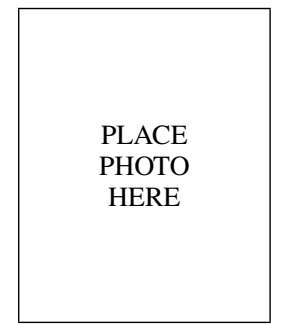

Simos A. Evangelou received the B.A./M.Eng degree in electrical and information sciences from the University of Cambridge, United Kingdom, in 1999 and the Ph.D. degree in control engineering from Imperial College London, in 2004. He is a senior lecturer in the department of electrical and electronic engineering at Imperial College London, after joining jointly the departments of mechanical and electrical and electronic engineering in 2006 . He is a member of IFAC technical committee Automotive Control. He is a Fellow of the Higher Education Academy and a Member of the IEEE, the ASME and the IET. 